\title{
ASSESSMENT OF THE LEVEL OF SURFACE ACTIVITY IN HUMPBACK WHALES DURING THE BREEDING SEASON
}

\author{
Fernando Félix ${ }^{1}$
}

\begin{abstract}
Between 1991 and 2002, the reproductive behavior of the humpback whale was studied during the breeding season off the coast of Ecuador, South America $\left(02^{\circ} \mathrm{S}, 81^{\circ} \mathrm{W}\right)$. During the sighting period the level of surface activity exhibited by the whales was assessed according to the type of display performed and its frequency. Five displays that produce percussion sounds and used likely for communication were considered: breaching, head-lapping, tail-slapping, flipper-slapping and tail slashing. A total of 289 selected sightings were included in one of four levels according to a scale of intensity designed for the purpose. To determine what social conditions increased or reduced the activity, groups were organized according to their size and age-class composition. Singletons and groups of three and four whales showed a significantly higher surface activity than pairs or larger than four for the highest intensity level $(\mathrm{P}<0.05)$. Differences were also found when age-classes were compared, with subadults showing significantly higher surface activity than other classes $(\mathrm{P}<0.01)$. Groups that increased members showed a significant difference respect to decreasing groups at the lowest level of intensity of the scale $(\mathrm{P}<0.05)$. Competitive groups showed a significant higher occurrence at intensity level 2 than other groups $(\mathrm{P}<0.05)$. No relationship was found between whale speed and surface activity. The possible influence of environment factors such as day hour, sea state, moon phase and "El Niño", was also assessed; none of which showed a clear trend to affect the intensity of whale surface activity. A discussion about the implications of these findings is provided as well as interpretations of possible meanings of some displays under different social contexts. This analysis indicates that social aspects rather than environment factors drive the surface activity of the humpback whales during the breeding season.
\end{abstract}

Resumen - Entre 1992 y 2002, se estudió el comportamiento de las ballenas jorobadas durante su temporada de reproducción en la costa de Ecuador, Sudamérica $\left(02^{\circ} \mathrm{S}, 81^{\circ} \mathrm{W}\right)$. Para ello se analizó la actividad de superficie exhibida por las ballenas de acuerdo al tipo de pautas mostradas y su frecuencia. Cinco pautas que producen sonidos de percusión y que son utilizadas probablemente como una forma de comunicación fueron evaluadas: salto de espaldas, salto de vientre, golpe de cola, golpe de aleta pectoral y latigazos con la cola. Un total de 289 avistamientos fueron usados en el análisis. Con el afán de determinar que condiciones sociales fueron causantes del incremento o la ausencia de la actividad de superficie, los grupos fueron organizados de acuerdo al tamaño del grupo y al tipo de individuos presentes. Los individuos solitarios así como los grupos formados por tres y cuatro ballenas mostraron un nivel de actividad de superficie significativamente más alto $(\mathrm{P}<0.05)$. Diferencias significativas también fueron encontradas cuando se comparó los grupos por clases de edades, siendo los subadultos quienes mostraron el mayor nivel de actividad $(\mathrm{P}<0.01)$. Los grupos que incrementaron de tamaño durante el período de avistamiento mostraron también una diferencia significativa en el nivel más bajo de la escala de intensidad usada con respecto a los que disminuyeron en número $(\mathrm{P}<0.05)$. Los grupos competitivos mostraron una ocurrencia significativamente más alta en un nivel medio de intensidad $(\mathrm{P}<0.05)$. No se encontró relación alguna entre la actividad de superficie y la velocidad de las ballenas. También se evaluó la posible influencia de factores ambientales como la hora del día, el estado del mar, la fase de la luna y el fenómeno El Niño, ninguno de los cuales mostró una influencia clara en el nivel de actividad de superficie. La discusión incluye algunas implicaciones de estos resultados así como una interpretación del significado de algunas de las pautas exhibidas bajo diferentes contextos sociales. El análisis aquí presentado indica que los aspectos sociales tienen una influencia mayor que los ambientales en la actividad de superficie de las ballenas jorobadas durante la temporada de reproducción.

Keywords: humpback whale, behavior, breeding season, Ecuador, Southeast Pacific.

\section{Introduction}

The Southeast Pacific stock of humpback whales (Megaptera novaeangliae) breeds along the coast of Ecuador and Colombia during the austral winter (June-October) (Clarke, 1962; Leatherwood and Reeves, 1983; Florez, 1991; Scheidat et al., 2000; Félix and Haase, 2001a). As in other breeding sites, humpbacks exhibit intense surface activity suggesting a complex social structure. Breaching, flipper-slapping and tail-slapping, among others, are displays frequently performed by animals of all age classes and in different social contexts. Surface activity is not exclusive of humpback whales; it has also been reported in other Mysticeti such as right whales Eubalaena australis (Sayman and Tayler, 1979) and less frequently and spectacularly in gray Eschrichtius robustus, blue Balaenoptera musculus and sei B. borealis whales (Slijper, 1979).
For the purpose of this paper, surface activity means a deliberate action exhibited by whales involving displays other than swimming and breathing, and specifically displays that produce non-vocal sounds. When hitting the surface with their bodies or flippers, whales produce sounds that travel several kilometers through the sea, and for this reason they may be used for communication or just to maintain acoustic contact (Herman and Tavolga, 1980; Tyack and Whitehead, 1983; Frankel et al., 1995). Herman and Tavolga mentioned some possible explanations to these displays including, exhibition, play, male competition, intimidation, sexual stimulation, food detection, and responses to wounds or irritation. Although the reproductive behavior of humpback whales has been extensively studied in their breeding grounds (e.g., Herman and Antinoja, 1977; Tyak and Whitehead, 1983;

\footnotetext{
${ }^{1}$ Fundación Ecuatoriana para el Estudio de Mamíferos Marinos (FEMM). PO Box 09-01-11905, Guayaquil, Ecuador. fernandofelix@femm.org
} 
Darling et al., 1983; Baker and Heman 1984; Silber, 1986; Clapham et al., 1992), the specific role of these displays in different social contexts is still poorly known.

Most of the surface activity during the winter would be related with breeding. For this reason one of the aspects most studied in humpback whales is the competition among males for receptive females. During pursuits, males exhibit threatening and aggressive displays such as charges, tail-slashing, head lunging, bubbling, and different types of vocalizations that may lead to agonistic fights (Tyak and Whitehead, 1983; Baker and Herman, 1993; Darling et al., 1983; Silber, 1986; Clapham et al., 1992). For this behavior involving much physical contact, short-range percussion sounds produced when hitting the surface with flippers and flukes may be important to define hierarchies, establish alliances or guide other whales. Other interesting aspect of the reproductive behavior of humpback whales is the production of songs. Possible functions for songs include sexual advertisement (Payne and Mc Vey, 1971; Winn and Winn, 1978; Tyack, 1981), ovulation synchronization (Baker and Herman, 1984), spacing mechanisms (Winn and Winn, 1978; Frankel et al., 1995) and social ordering (Au et al. 2000; Darling and Bérubé, 2001; Craig et al., 2002). Although songs and other phonation sounds may travel further away and contain more information than percussion sounds, the later might be easily located by other whales nearby and may convey information related to local social activities that could require an immediate response. It would not make sense to spend all that energy if it does not convey a short-term response from which the expender may obtain some benefit.

This paper analyzes the level of surface activity exhibited by groups of humpback whales breeding off Ecuador to determine what conditions favor or reduce such activity. To accomplish the task, an arbitrary scale of four levels of intensity was used to evaluate the behavior of the whales and to determine a possible relationship between social structure (group size, composition and stability) and surface activity. The possible influence of environment conditions such as sea state, moon phase, time of day, and "El Niño" on whale behavior was analyzed. In some cases an interpretation of the possible meaning of displays repeated systematically is proposed.

\section{Material and Methods}

A total of 201 trips aboard whalewatching boats were made between 1991 and 2002 to study humpback whale behavior during the breeding season (June-October) in three different sites off the coast of Ecuador $\left(02^{\circ} \mathrm{S}, 81^{\circ} \mathrm{W}\right)$ : Puerto López, Puerto Cayo and Salinas (Figure 1). At least 10 different boats were used, including open boats of $6-8 \mathrm{~m}$ length with outboard motor and yachts up to $15 \mathrm{~m}$ in length with twin stationary engines. Groups of whales were observed at distances of 50-200m for periods ranging between 2 and 150 minutes. During observations, information about the number of animals, age-class composition, geographic position and behavior was taken. Table 1 shows the total observation effort by year as well as information related to number of whales sighted. Details of the methodology can also be found in previous reports (e.g., Félix and Haase, 1998, 2001a, 2001b).

A group was defined as the total number of animals within $100 \mathrm{~m}$ radius (even singletons), moving in the same direction and generally exhibiting similar behaviors (i.e. synchronized diving-breathing pattern). Although other groups were often seen nearby $(200-3000 m)$, they were not considered as part of the group unless there was obviously interaction with the group initially followed (Félix and Haase, 1998). Only those groups actively followed by the boat were taken into account for statistical analysis. The number of whales was recorded at the beginning and at the end of the observation period or when evidently other group was met, which provided the basis to establish if groups changed by affiliation or disaffiliation. When there was doubt on the exact number of whales present, a range was annotated and later averaged for statistical purposes.

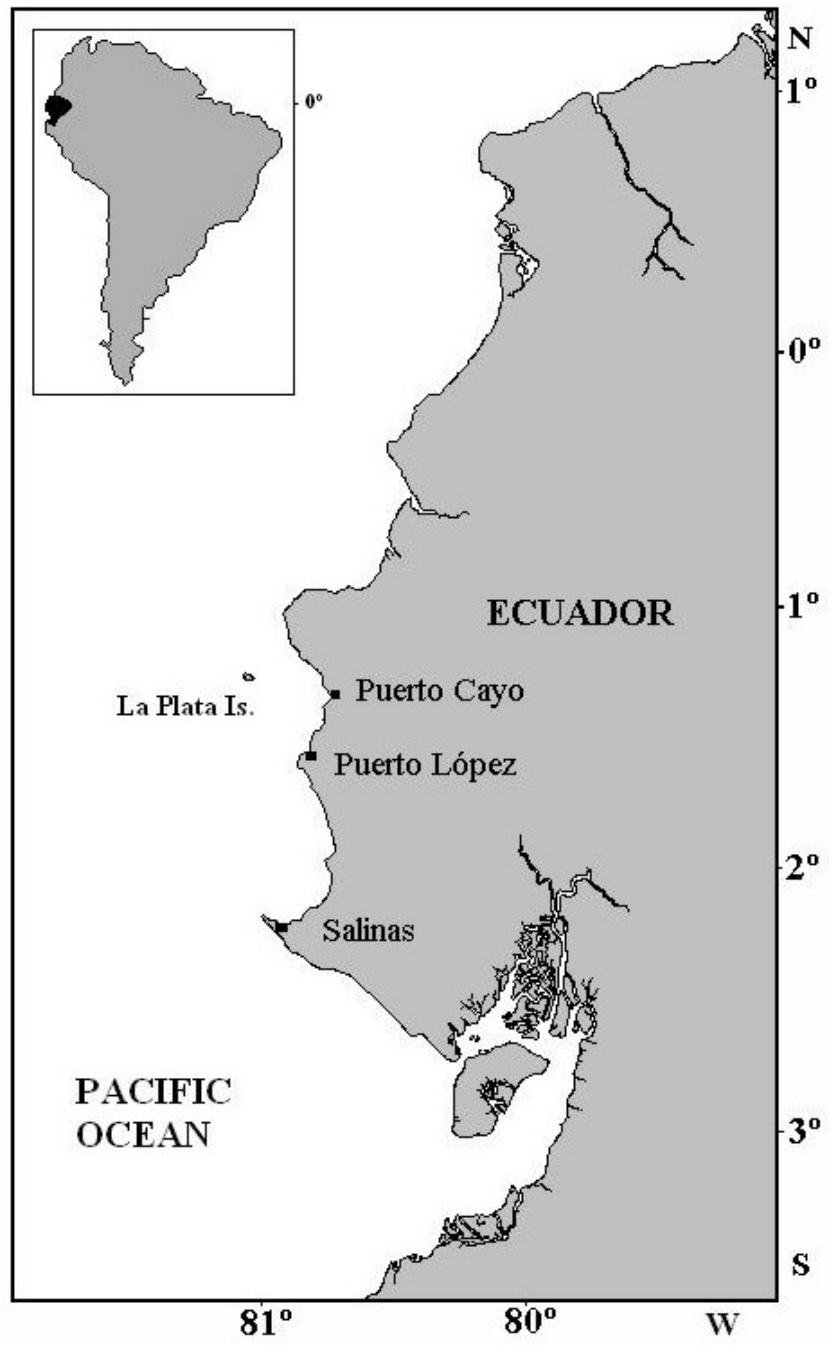

Figure 1. The coast of Ecuador and sites surveyed. 
Sites and surveys

Puerto López. Trips were carried out from this port between 1991 and 1997 and also in 2000 (Table 1, Figure 1). Boats left port heading northwest towards La Plata Island, some $40 \mathrm{~km}$ offshore, along the $50 \mathrm{~m}$ isobath. After 3 hours the boat returned to Puerto López.

Puerto Cayo. Trips were carried out in 1996 and 1997. The site is located $22 \mathrm{~km}$ north of Puerto López and the operation was carried out closer to shore in shallower waters (20m depth average). Boats left port in a westbound direction heading up to $20 \mathrm{~km}$ offshore and then returning to port.

Salinas. Trips were carried out in 2001 and 2002. This site is located $70 \mathrm{~km}$ south of Puerto López at the westernmost tip of Ecuador. Surveys from Salinas were shorter extending $6-10 \mathrm{~km}$ west; and quickly reaching depths of 50-60m.

Composition

The age-class of animals was established based on their relative size. Three age-class categories were assigned: adults (large animals $>10 \mathrm{~m}$ in length), subadults (mid-size animals $6-10 \mathrm{~m}$ in length) and calves (smaller animals $<6 \mathrm{~m}$ in length and always accompanied by an adult animal, presumably the mother). This interpretation must be taken with caution since the subjective criteria to assign categories is based on the experience of the author. Once age-classes were identified, groups were placed in one of the following five categories: (A) all adults, (S) all subadults, (AS) adults with subadults, (MC) mother with calf, (ME) mother with calf and one or more escorts.

\section{Levels of activity}

Information related to behavior included both qualitative and quantitative aspects of five of the main energetic displays observed in this species: breaching, headslapping, tail-slapping, flipper-slapping and tail-slashing. Based on the number of displays exhibited and the number of times they were repeated, a level of intensity for surface activity was assigned as one of four categories: 1) the highest level, if whales repeated more than 10 times one or more displays or if at least 3 different displays were executed during the sighting; 2 ) medium level, when one or two displays were repeated up to 9 times; 3 ) low level, when one display was just occasionally executed (1-2 times); and 4) the lowest level, when no display was executed. Hereinafter levels of activity will be referred to by numbers (1 to 4$)$.

Table 1. Observation effort and number of sightings and individual whales recorded by site during the study period.

\begin{tabular}{|c|c|c|c|c|c|c|c|c|c|c|c|}
\hline SITE & 1991 & 1992 & 1993 & 1994 & 1995 & 1996 & 1997 & 2000 & 2001 & 2002 & TOTAL \\
\hline \multicolumn{12}{|l|}{ PUERTO LÓPEZ: } \\
\hline Trips & 7 & 5 & 2 & 7 & 16 & 28 & 24 & 8 & & & 97 \\
\hline Sightings & 17 & 8 & & & 43 & 64 & 50 & 24 & & & 206 \\
\hline Number of whales & 39 & 29 & & & 112 & 171 & 130 & 49 & & & 528 \\
\hline Navigation time (min) & 2400 & 2335 & 624 & 2838 & 7840 & 10678 & 5827 & 1352 & & & 33849 \\
\hline Observation time (min) & 586 & 773 & 54 & 594 & 1360 & 1655 & 1294 & 443 & & & 6758 \\
\hline Total time & 2986 & 3108 & 678 & 3432 & 9200 & 12333 & 7121 & 1795 & & & 40652 \\
\hline \multicolumn{12}{|l|}{ PUERTO CAYO: } \\
\hline Trips & & & & & & 21 & 16 & & & & 37 \\
\hline Sightings & & & & & & 41 & 31 & & & & 72 \\
\hline Number of whales & & & & & & 27 & 72 & & & & 99 \\
\hline Navigation time (min) & & & & & & 4305 & 4290 & & & & 8595 \\
\hline Observation time (min) & & & & & & 1623 & 1146 & & & & 2769 \\
\hline Total time & & & & & & 5928 & 5436 & & & & 11364 \\
\hline \multicolumn{12}{|l|}{ SALINAS: } \\
\hline Trips & & & & & & & & & 32 & 35 & 67 \\
\hline Sightings & & & & & & & & & 68 & 78 & 146 \\
\hline Number of whales & & & & & & & & & 160 & 174 & 334 \\
\hline Navigation time (min) & & & & & & & & & 4136 & 3961 & 8097 \\
\hline Observation time (min) & & & & & & & & & 1953 & 2061 & 4014 \\
\hline Total time & & & & & & & & & 6089 & 6022 & 12111 \\
\hline
\end{tabular}




\section{Results}

\section{Global and seasonal level of surface activity}

A total of 424 groups were observed during ten seasons. The first groups were recorded as early as the end of May and the last groups as late as the first days of October, with sightings concentrated between July and September. The weekly frequency distribution of sightings is shown in Figure 2. Only observations lasting more than 15 minutes were taken into account, resulting in 289 sightings retained for the analysis. According to the criteria used to define the level of activity, the observed global level of surface activity (all data pooled) was as follows: level 1, 68 groups (23.5\%); level 2, 45 groups (15.6\%); level 3, 52 groups (18\%) and level 4, 124 groups $(42.9 \%)$. These figures provide the first indication as to how frequently whales exhibited displays on the surface and form the basis for comparison of activity levels under different conditions considered.

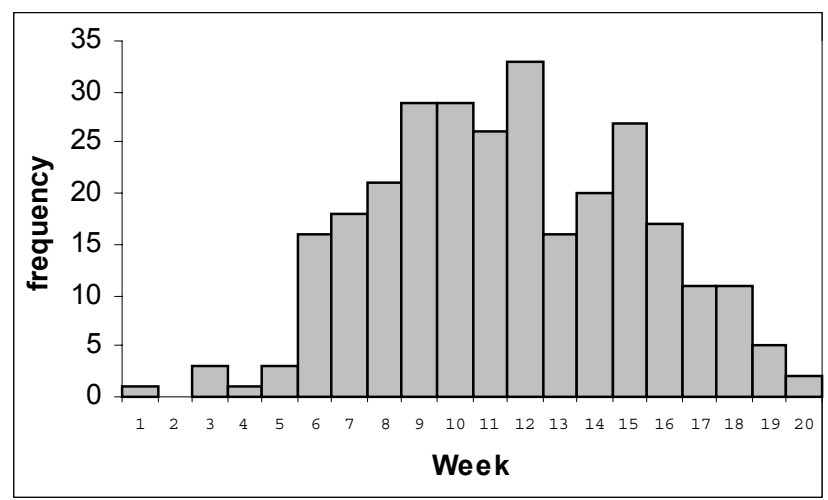

Figure 2. Seasonal distribution of sightings.

Figure 3 shows the monthly mean level of activity between June and September, when $99 \%$ of the sightings were recorded $(n=286)$. June was the month with the lowest observed level of surface activity for the entire season, with the lowest values for levels 1 and 2 and the highest values for levels 3 and 4 . Surface activity peaked during July and August, where the highest values for levels 1 and 2 and the lowest values for levels 3 and 4 were recorded. In September levels 1 and 2 decreased but remained higher than in June, whereas levels 3 and 4 increased slightly though not reaching June values. Despite these differences, when frequencies were compared with the Chi square test no significant difference was found in any level, although June was excluded from the analysis of levels 1 and 2 because of the low number of sightings $\left(X^{2}=1.93\right.$ for level $1, X_{2}^{2}=0.69$ for levels $2, X_{3}^{2}=2.06$ for level 3, and $X_{3}^{2}=1.14$ for level 4; P>0.05 in all cases). These results would indicate that the level of surface activity in a global context is most likely to be constant during the whole season.



Figure 3. Monthly average level of surface activity. Numbers (14) indicate the scale of intensity: (1) high; (2) medium; (3) low; and (4) no display observed.

\section{Level of surface activity and group structure}

\section{Group size}

Groups in general were small with an average of 2.58 individuals/group $(s=1.43$, range $1-11)$. The modal value was two $(n=122,42.2 \%)$, with 48 singletons $(16.6 \%), 55$ triplets $(19.3 \%), 39$ quads $(13.5 \%)$, and 25 groups of size $>4$ $(8.6 \%)$. Figure 4 shows the level of activity for each group size category. Singletons showed high values for levels 1 $(33 \%)$ and $4(46 \%)$, but the lowest value for level 2 (6.6\%). Pairs showed lower values of activity level 1 than singletons $(14.7 \%)$, but higher values in levels 2 and 3 (17.2\% and $24 \%$ respectively) and similarly for level of activity $4(44.2 \%)$. Triplets showed the highest values for levels 1 (36\%) and $2(20 \%)$ and the lowest value for level 4 $(31 \%)$ of all categories. Quads showed levels of activity similar to triplets, with high values for levels 1 and 2 and a low value for level 4 . The level of activity decreased in groups larger than 4 , showing the lowest value for level 1 $(8 \%)$, the second lowest for level $2(17 \%)$, and the highest values for levels $3(24 \%)$ and $4(56 \%)$. The comparison of the frequencies showed a significant difference in the highest level of activity (level 1) as a function of group size $\left(X_{3}^{2}=13.23, P<0.05\right)$.

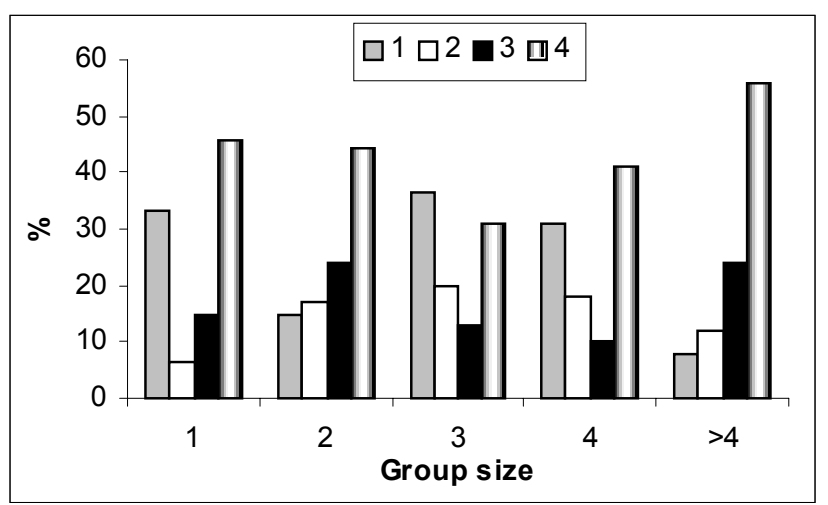

Figure. 4. Level of surface activity and group size. Numbers (1-4) indicate the scale of intensity: (1) high; (2) medium; (3) low; and (4) no display observed. 


\section{Group composition}

The age-class of every member of a group was determined for 188 groups (Table 2). Most groups were assigned to two categories: all adults (A) (54.7\%) and adults with subadults (AS) (22.8\%). Groups containing a mother with calf accounted for $15.4 \%$ of the groups observed (MC + $\mathrm{ME})$. Groups of subadults (6.9\%) consisted of singletons, except for one pair. Table 2 also shows the average group size of each category.

Table 2. Age-class group composition, frequency of sightings and average group size.

\begin{tabular}{lccl}
\hline \hline AGE-CLASS GROUP & \multicolumn{2}{c}{ SigHTED GROUPS } & \multicolumn{1}{c}{$\begin{array}{c}\text { AVERAGE } \\
\text { GROUP size }\end{array}$} \\
\hline \hline All adults (A) & $\mathrm{n}$ & $\%$ & \\
Adults and subadults (AS) & 43 & 22.8 & $3.19(\mathrm{~s}=1.7)$ \\
All Subadults (S) & 13 & 6.9 & $1.08(\mathrm{~s}=0.28)$ \\
Mother/calf pair (MC) & 18 & 9.6 & 2 \\
Mother/calf + escorts (ME) & 11 & 5.8 & $3.86(\mathrm{~s} .1 .48)$ \\
\hline \hline
\end{tabular}

Figure 5 shows the level of activity by age-class groups. All adult groups (A) showed the lowest value for the level $1(23 \%)$, but intermediate values for levels $2(18 \%)$ and 3 (19\%). AS groups showed a higher value for level 1 (32.5\%) than A groups, a similar value for levels 2 (21\%) and $3(16 \%)$ and a lower value for level 4 (30\%). S groups (singletons) were more active than A and AS groups showing extreme values for levels 1 (92.3\%) and 4 (7.7\%), and no observations for levels 2 and 3. Mother/calf pairs (MC) showed a similar level of activity as in A and AS groups for level 1 (27.7\%), but low values for levels $2(11.1 \%)$ and $3(5.5 \%)$, and the highest value for level 4 (55.5\%). Mothers with calves showed greater surface activity when one or more escorts were present: they showed the second highest value for level $1(36.3 \%)$, which is higher than that obtained for mother/calf pairs alone, no observations for level 2, a marked increase for level 3, and a reduction for level 4 . Because of the low number of frequencies in several categories, statistic comparisons were made only for levels 1 and 4 ; in both cases the difference was highly significant $\left(X_{4}^{2}=17.7\right.$ for level 1 , and $X_{4}^{2}=26.63$ for level $\left.4, \mathrm{P}<0.01\right)$.

Displays exhibited by the different age-class groups are compared in Figure 6. The figure only indicates the presence of a display and not the observed frequency during the sighting period. All displays were seen within all age-classes, except tail-slashing, which was not observed in S groups. Breaching was recorded more frequently in S groups $(56 \%)$ than in the remaining age-classes (35-39\%). Head slapping, a display especially exhibited by calves, was more frequent in MC groups $(28 \%)$ than in the remaining $(12-18 \%)$. Tail-slapping was more frequent in A groups (22\%) than in the remaining classes (7.7-12.5\%), and less frequent in ME groups. Flipper-slapping was more frequent in A and AS groups (mean 18.55\%) than in the



Figure 5. Group composition and level of surface activity. Numbers (1-4) indicate the scale of intensity: (1) high; (2) medium; (3) low; and (4) no display observed.

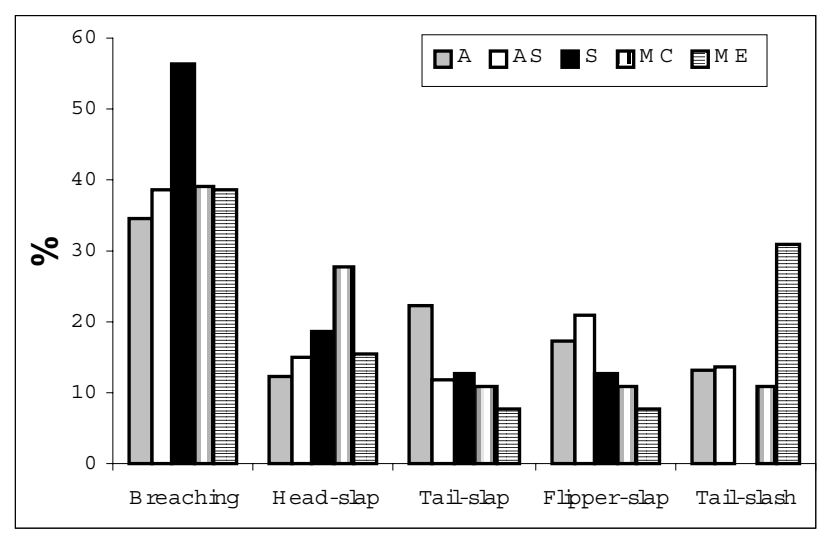

Figure 6. Proportions of occurrence of five displays exhibited by age and sex class groups.

remaining groups (7.7-12.5\%), with ME groups showing the lowest proportion. Tail-slashing was more frequent in ME groups $(30.7 \%)$ than in the remaining age-classes (0$15 \%)$ and was never recorded for $S$ groups. Despite these differences, the comparisons carried out did not indicate significant differences in frequency by age-class, although the low frequencies in some categories did not allow a complete analysis.

\section{Groups that changed size}

Changes in the number of individuals were recorded in 42 groups (14.5\% of the total). Unstable groups were more frequently seen between mid-June and the first week of September and were larger than the average (mean $=3.54$ ind/group, $s=1.77$ ). The number of individuals changing in these groups ranged between 1 and 4 . Differences in average group size were noticeable between increasing and decreasing groups. The average size of increasing groups went from 2.59 to 4.39 ind/group (mean=3.49, $s=1.89, n=21$ ); whereas decreasing groups went from 4.38 to 2.74 ind/group (mean=3.56, $s=1.66, n=21$ ). Most unstable groups were all adults (A) $(n=17,40 \%)$ and adults with subadults (AS) $(n=12,28.5 \%)$. Only one group included a mother/calf pair and one escort. 
The level of activity of unstable groups is compared with groups that did not change members in Figure 7. Unstable groups had higher values for level 1, for level 2 , and for level 3 and lower value for level 4. Although it seems there is a generalized trend to increase the level of activity in unstable groups, it must be noted that only for level 4 the difference resulted statistically significant $\left(X^{2}=5.71, \mathrm{P}<0.05\right)$.

There were also differences in the level of activity between increasing and decreasing groups (Figure 8). However, those differences were not statistically significant.

Different proportions in the exhibition of the evaluated displays, particularly those involving slaps on the surface, were also observed between both types of unstable groups (Table 3). Breaching, head-slapping and tailslashing were seen in the same proportion in both classes of groups, but flipper-slapping and tail-slapping were evidently more frequent in increasing groups (4.5 and 8 times, respectively). The low frequency of these two displays in decreasing groups precluded statistical comparisons.

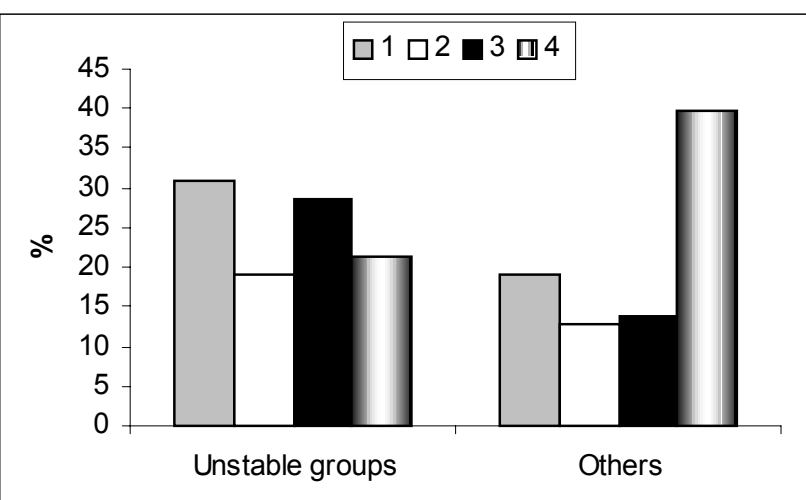

Figure 7. Comparison of the level of surface activity of unstable groups in respect to the rest of groups. Numbers (1-4) indicate the scale of intensity: (1) high; (2) medium; (3) low; and (4) no display observed.

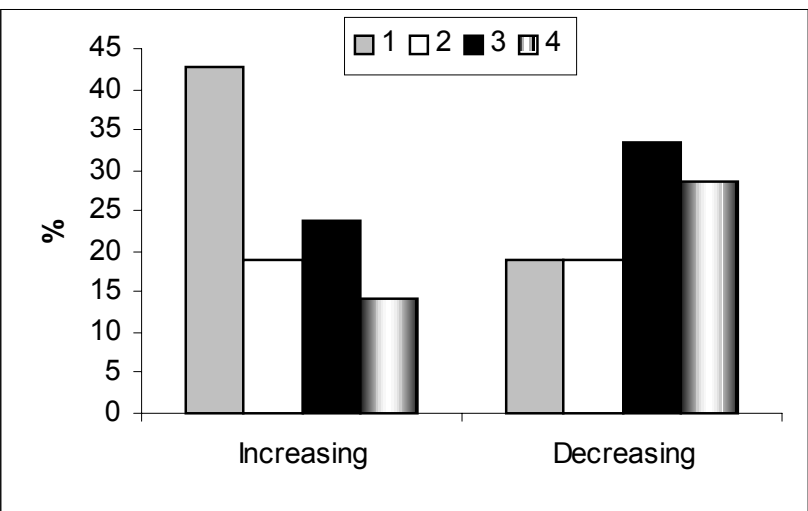

Figure 8. Comparison of the level of surface activity between groups that increased and groups that decreased members during the sighting period. Numbers (1-4) indicate the scale of intensity: (1) high; (2) medium; (3) low; and (4) no display observed.
Table 3. Frequency of displays exhibited by increasing $(\mathrm{n}=21)$ and decreasing $(n=21)$ groups.

\begin{tabular}{lcc}
\hline \hline DISPLAY & INCREASING & DECREASING \\
\hline \hline Breaching & 10 & 9 \\
Head-slapping & 5 & 4 \\
Tail-slapping & 9 & 2 \\
Flipper-slapping & 8 & 1 \\
Tail-slapping & 6 & 5 \\
\hline \hline
\end{tabular}

Competitive groups

Thirty-nine competitive groups were recorded $(13.5 \%$ of the total); most of them were all male groups (A) $(n=30,77 \%)$ and the remaining adult with subadult groups (AS) $(n=9,23 \%)$. Competitive groups were the largest recorded (mean $=4.36$ inds/group, $s=1.58$ ) and included 19 groups (45\%) classified also as unstable. Figure 9 shows a comparison of the surface activity between competitive groups and the rest of the groups. Values for levels 1 and 4 were similar in both type of groups, but competitive groups showed a higher value for level $2(33.3 \%)$ and a lower value for level 3 . Significant differences in frequencies were found for level $2\left(X^{2}=5.9, P<0.05\right)$, indicating that competitive groups may be characterized by moderate levels of activity during their frenetic pursuit.

\section{Level of surface activity and whale speed}

Whale speed was estimated for 76 groups. Figure 10 shows the frequency distribution of velocities in $1 \mathrm{~km} / \mathrm{h}$ intervals. Whales moved at an average speed of $4.53 \mathrm{~km} / \mathrm{h}(s=2.81$, range $0.17-14.24 \mathrm{~km} / \mathrm{h}$ ). For comparison, speeds where organized in three ranges: slow, $0-2.9 \mathrm{~km} / \mathrm{h}(n=21,25.6 \%)$; medium, $3-6.9 \mathrm{~km} / \mathrm{h}(n=46,58.5 \%)$; and fast, $7-14.9 \mathrm{~km} / \mathrm{h}$ $(n=9,15.8 \%)$. This classification was arbitrary and was established based on the homogeneity of the observed frequency distribution.

Figure 11 shows the level of surface activity in each speed category. Slow speed groups showed the lowest value for level $1(19 \%)$, the highest value for level $3(19 \%)$ and average values for levels 2 and 4 . Medium speed groups showed the highest values for levels $1(24 \%)$ and $2(22 \%)$ and the lowest value for level 4 . The fastest groups showed the lowest values for levels 2 and 3 and the highest value for level 4 . A statistical comparison was not possible because of the small numbers of frequencies in some categories. Instead, velocities were compared for each level of activity. The fastest groups (mean $=4.56 \mathrm{~km} /$ $h, s=3.6, n=32$ ) were those that exhibited the lowest level of surface activity (level 4). They were followed by groups in level $1($ mean $=4.53 \mathrm{~km} / \mathrm{h}, s=2.08, n=15)$, level 3 (mean $=4.35, s=2.98, n=12)$ and level $2($ mean $=4.01 \mathrm{~km} / \mathrm{h}, \mathrm{s}=2.08$, $n=15)$. The velocities of each level were not significantly different (ANOVA, $F_{3,72}=0.66, P>0.05$ ). Therefore, a relationship between the intensity of surface activity and whale speed was discarded. 
The fastest groups were those composed by all subadults (S), followed by all adults (A), adults with subadults (AS) and mother/calf pairs, although the frequency for some age classes are too small for statistical comparison (Table 4).

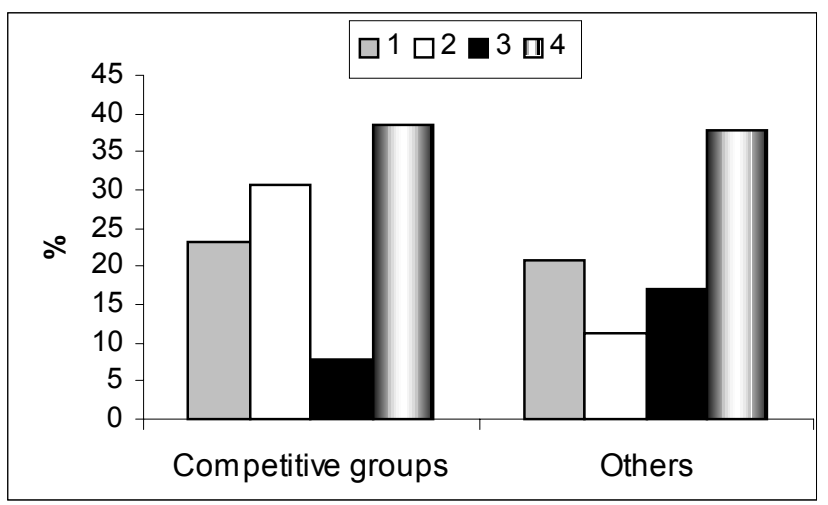

Figure 9. Comparison of the level of surface activity between competitive groups and the rest of groups. Numbers (1-4) indicate the scale of intensity: (1) high; (2) medium; (3) low; and (4) no display observed.



Figure 10. Distribution frequency of whale speeds.

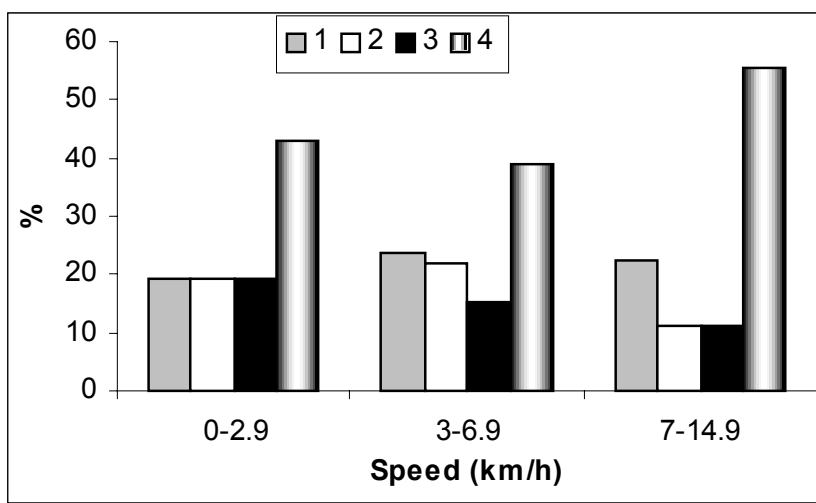

Figure 11. Level of surface activity regarding speed. Numbers (14) indicate the scale of intensity: (1) high; (2) medium; (3) low; and (4) no display observed.
Table 4. Speed of the whales by age-class groups.

\begin{tabular}{lcc}
\hline \hline AGE-CLASS & $\begin{array}{c}\text { NuMBER } \\
\text { OF GROUPS }\end{array}$ & $\begin{array}{c}\text { AvERAGE SPEED } \\
(\text { KM } / \mathrm{H})\end{array}$ \\
\hline \hline All adults (A) & 34 & $4 . .68(\mathrm{~s}=2.89)$ \\
Adults and subadults (AS) & 11 & $4.15(\mathrm{~s}=1.6)$ \\
All Subadults (S) & 2 & $8.35(\mathrm{~s}=0.87)$ \\
Mother/calf pair (MC) & 3 & $3.56(\mathrm{~s})=1.9)$ \\
\hline \hline
\end{tabular}

Level of surface activity and environment factors

In order to determine if surface activity is also influenced by variables other than social factors, the level of surface activity was analyzed regarding environment factor such as time of day, sea state, moon phase and "El Niño" events.

Time of day

Since the survey effort was concentrated in morning hours, most of the sightings $(n=222,79 \%)$ occurred between 06:00 and 13:00 hours (Figure 12). The level of surface activity by hour of day is shown in Figure 13. Time intervals with less than 10 sightings were discarded to reduce bias. The highest values for levels 1 and 2 were recorded between 13:00 and 16:00 hours and the lowest values between 12:00 and 13:00 hours. The highest value for level 3 was recorded between 11:00 and 12:00 hours and the lowest value between 13:00 and 14:00. The highest value for level 4 was recorded between 12:00 and 13:00 hours and the lowest value between 15:00 and 16:00 hours. In general, afternoon hours showed higher values for levels of greater activity (levels 1 and 2) and lower for levels 3 and 4 than morning hours. However, this is likely a sampling artifact since morning hours with few samples also showed great heterogeneity. Due to differences in frequencies between morning and afternoonevening periods, data were pooled in two categories, morning (06:00-13:00) and afternoon (13:00-19:00), and then compared. No significant differences in any activity level between morning and afternoon hours were observed $\left(X^{2}<1\right.$ for all four levels, $\mathrm{P}>0.05$ ).

\section{Sea state}

Sea state conditions were recorded in 179 sightings. In general, sea state conditions were good and constant along the season. Most of the sightings were made in Beaufort $2(n=151,84.3 \%)$ and the remaining in Beaufort $3(n=28,15.64 \%)$. Figure 14 shows the comparison between both oceanographic conditions. In Beaufort 3 state the level of activity 1 (37\%) was higher and the level of activity 2 was $(7.4 \%)$ lower than in Beaufort 2 (23.8\% and $16.6 \%$ respectively). Although these results show a trend to increase the surface activity from level 2 to level 1 during Beaufort 3, the difference was not statistically significant for level $1\left(X^{2}=1.01, P>0.05\right)$ and for level 2 there were not enough frequencies for comparisons. Differences between the other two categories (levels of activity 3 and 4 ) were non-significant $\left(X^{2}<1\right.$ in both cases, $\left.P>0.05\right)$. 

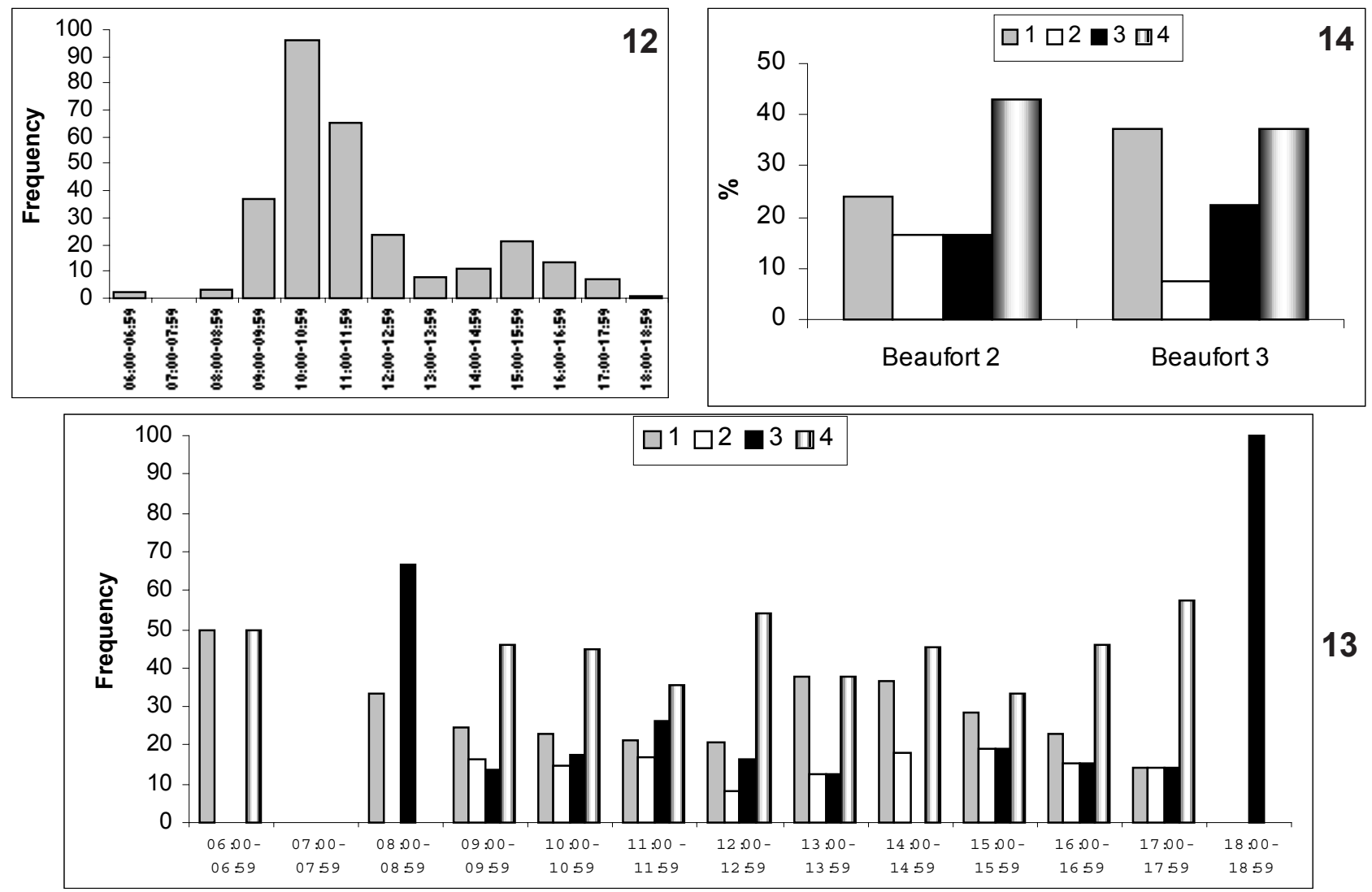

Fig 12. Frequency distribution of sightings by hour of day. Figure 13. Level of surface activity by time of day. Numbers (1-4) indicate the scale of intensity: (1) high; (2) medium; (3) low; and (4) no display observed. Figure 14. Comparison of the level of surface activity regarding sea state. Numbers (1-4) indicate the level of intensity of whale activity: (1) high; (2) medium; (3) low; and (4) no display observed.

\section{Moon phase}

The moon phase drives the tidal cycle and regulates important physiological cycles in nature. To test for the potential effect of moon phase on whale surface activity, comparisons in activity levels over a period of five days, ranging from two days before and two days after, the full $(n=45)$ and new $(n=43)$ moon were made with the remaining days (Figure 15). A higher level of activity was obtained during the new moon period, when the highest values for levels 1 and 3 (28\%) and the lowest values for level 2 (14\%) and $4(30 \%)$ were found. However, those differences were not significant $\left(X_{2}^{2}=0.42,0.21,3.6\right.$ and 2.07, $\left.\mathrm{P}>0.05\right)$.

\section{"El Niño"}

The Southeast Pacific region is affected by "El Niño", oceanatmospheric anomaly which has a periodicity of 4-5 years. One of the most notorious manifestations of this phenomenon is the increase of the mean sea surface temperature, which produces ecological disruptions with disastrous effects in almost every trophic level (Barber and Chavez, 1983). Figure 16 shows a comparison of the surface activity for four seasons with the largest number of sightings, including two "El Niño" years (1997 and 2002) and two "normal" years (1996 and 2001). All these years accounted for 240 sightings (83\% of the total). During "El Niño" event of 1997 the mean sea surface temperature in the Southeast Pacific showed a positive anomaly ${ }^{2}$ of $4^{\circ} \mathrm{C}$ during the whole breeding season, whereas during "El Niño" event of 2002 the mean sea surface temperature showed a negative anomaly ${ }^{3}$ between 0.5 and $1^{\circ} \mathrm{C}$, although along the central Pacific the anomaly was positive with values between 1 and $2^{\circ} \mathrm{C}$. Except for level 2, there was a high inter-annual variability in the remaining levels. In the years 1996 and 2002 ("El Niño") values for level 1 were similar (around 30\%). The same occurred in the years 1997 ("El Niño") and 2001, although in this case the observation of level 1 activity was lower $(17.7 \%$ and $22 \%$ respectively). During the most intense "El Niño" year (1997) the lowest value for the most intense level of activity (level 1) and the highest value for the level without surface activity (level 4) were observed. However, differences were not significant for any level of surface activity $\left(X_{3}^{2}=2.62,0.12,3.91\right.$ and $4.85, \mathrm{P}>0.05)$, which would mean that inter-annual variations recorded probably occurred by chance.

${ }^{2}$ Information about sea surface temperature for 1997 was provided by the "Instituto Oceanográfico de la Armada de Ecuador (INOCAR)" (Oceanographic Institute of the Navy of Ecuador). These figures were published in Félix and Haase (2001b).

${ }^{3}$ Information from NOAA/National Weather Service, National Centers for Environmental Prediction, Climatic Prediction Center (www.cpc.ncep.noaa.gov/products/analysis_monitoring/enso_update). 



Figure 15. Comparison of the level of surface activity and moon phase. Numbers (1-4) indicate the scale of intensity: (1) high; (2) medium; (3) low; and (4) no display observed. Figure 16. Comparison of the level of surface activity between "El Niño" years (1997 and 2002) and non-“El Niño" years (1996-2001). Numbers (1-4) indicate the scale of intensity: (1) high; (2) medium; (3) low; and (4) no display observed.

\section{Discussion}

\section{Social structure influence}

The breeding season is a critic period when energy stored during the feeding season must be used rationally to obtain a maximum benefit. It may be inferred that the intense surface activity exhibited by humpback whales during the breeding season must have an extremely important role for their social organization. In humpback whales the social ordering seems to be transitory and characterized for fluid associations among individuals (Darling et al., 1983; Baker and Herman, 1984; Mobey and Herman, 1985; Clapham et al., 1992; Felix and Haase, 2001a, Valsecchi, 2002), in most cases limited to moments of courtship, male competence and mating, The dynamics that characterizes groups of humpback whales during the breeding season would show the "prospecting" and aggressive behavior that mature males display when looking for receptive females (Mobey and Herman, 1985). Those who invested the most would be males looking for an opportunity to mate with females having the largest reproductive potential (Tyack and Whitehead, 1983; Craig et al., 2002).

The most active groups were those composed by three and four adults (A) or by adults with subadults (AS). This seems to be the case of competitive groups that would form when one or more males detect a receptive female. However, as demonstrated when the surface activity was analyzed regarding group size, the intensity of surface activity decreased with group size, therefore most of the surface activity would be produced at the beginning, when competitive groups form and start growing. It is possible that during this initial activity, competitive males establish a hierarchical ordering as suggested to exist in this type of groups (Tyack and Whitehead, 1983; Baker and Herman, 1984; Silber, 1986; Clapham et al., 1992). Besides increasing surface activity, Silber (1986) stated that the entry of a new member to the group produces a significant increase of the social vocalization rate (no songs). Once competitive groups are well established, the surface activity with breaching and slapping on the water surface with flippers and flukes decrease to continue with the pursuing of the female, which originates the presence of other displays typical of competitive groups and described formerly. Such depiction agreed with Silber (1986) who also reported a negative correlation between surface activity and group size, but opposed to Tyack and Whitehead (1983) who reported a direct relationship between group size and activity. This difference is basically due to how "activity" is defined, since Tyack and Whitehead evaluated other type of displays related rather with competitive behavior such as tail-slashing, bubbling and head lunging.

Another clue supporting the idea that competitive groups show a higher level of surface activity at their formation than when they are in the pursuit comes from the difference of displays exhibited when groups increased or reduced members. Groups that increased their members showed a higher frequency of displays producing percussion sounds at the surface (flipper slapping and tail slapping) observed in 14 of 20 groups (70\%) compared with 4 of $21(19 \%)$ in those groups that decreased in number. These sounds would be produced by males with the purpose to call the attention of other males around to initiate the pursuing of a receptive female that has been located. Such behavior would support the findings of Clapham et al. (1992) and Brown and Corkeron (1995) who suggested that males join and cooperate with other males to have access to receptive females. Darling and Bérubé (2002) analyzed interactions between singing males and whales attracted toward them, also suggested that males convene in groups around a singer male to join competitive groups, using the songs as a way to facilitate the organization of such associations. Darling and Bérubé also stated that breaching was a common part of the interaction when a singer joined a group of whales containing a female, but when males joined for short time only 4 of 18 (22\%) occasions repeated energetic behaviors were seen on the surface such as flipper and tail slapping. Frankel et al. (1995) also reported the case of a singer that joined a whale after it had breached and performed a series of tail-slaps on surface. Baker and Herman (1984) reported the presence of repeated tail slaps in competitive groups; in one of them, after a secondary 
escort hit the surface repeatedly six times, other three secondary escorts immediately left the group and moved in another direction. Such observations support the hypothesis presented here that grouping competitive males would be an important function of tail slapping. However, Baker and Herman suggested that this display is rather a reaction of the females to the aggression and advancement of competitive males. Although in this study it was not possible to determine the sex of the whales that slapped on the surface, it seems less probably they were females trying to avoid competitive males because this noisy display only would alert of her presence to other males around. If females had succeeded in driving males away with this display, it had been recorded more frequently in groups with disaffiliations, which was not the case but the opposite. Tail-slashing would be a more appropriated and less noisy display to be used by females when refusing male advances, and noisier displays such as tail-slapping, flipper-slapping and breaching the reaction of the male calling for other males to form a competitive group. It is not discarded that tail slapping could have different connotations for other types of groups, and that is why all age-class groups also exhibit the display, although less frequently. Displays exhibited at breeding grounds, may even have an opposite meaning at feeding grounds; for example, Whitehead (1982) found that flippering occurred significantly more frequent in splitting groups.

Competitive groups were not always composed of only adult animals; in nine groups $(21.4 \%)$ there were subadults present (seven cases with one subadult and three cases with two subadults). These results are concordant with findings in Hawaiian breeding whales where Spitz et al. (2002) analyzed the size of the whales in competitive groups and found that one third of the secondary escorts have 0.5 probabilities to be immature. It is interesting to recall that adults with subadults groups (AS) had a surface activity level 1 of higher than groups composed only by adults (A), which would indicate that competitive groups in formation containing one or more subadults exhibit the highest level of surface activity. Frequently, it has been observed that in this type of group (AS) the same animal (usually an immature whale) is who breaches most of the time, possibly as an attempt to show other mature animals its readiness to compete for a female and participate in a competitive group. Another possible explanation is that the young active animal is the yearly calf of the pursued female trying to drive away suitors. Silber (1986) also informed that one whale is responsible for the production of most of the surface displays, although attributing the role to the principal escort as a way of threatening and disagreeing with other males.

Singletons have a contrasting level of surface activity, with a high proportion of individuals with the highest level of activity (level 1) but also with a high proportion of individuals with no surface activity (level 4). A major proportion of the more active singletons would correspond to subadults, since this age-class showed the highest level of activity of all age-classes for level 1 (73\%). As mentioned above, immature animals are trying to call attention to either females or other adult males to participate in competitive groups. On the other hand, singletons with scarce level of surface activity would include, traveling and resting animals as well as singing males that generally stay motionless for long period of time slow moving near the surface (Winn and Winn, 1978; Tyack 1981; Darling et al., 1983; Silber, 1983; Frankel et al., 1995; Ojeda and Hurtado, 1992; Darling and Bérubé, 2001; Spitz et al., 2002).

Pairs of whales were the second class with the lowest value for the surface activity level 1 after groups with more than four whales. Brown and Corkeron (1995) found that most pairs were composed by a male and a female and suggested it is due to a mate guarding strategy of males that would accompany females during the north migration to secure mating when females become receptive. Valsecchi et al. (2002) demonstrated that there was never more than one adult female in the same group. Pairs of whales were $42 \%$ of the groups, suggesting that most of the adult females in the population are integrating this type of group. These findings also suggest that males display most of the surface activity during the breeding season and most of such behavior is related to reproduction. When limiting the surface activity, females save energy for gestation, lactating and nursing. However, females seem to increase the surface activity when they become mothers, as shown by the high value for the level 1 of MC and ME groups. It cannot be discarded that mature females may exhibit some type of surface display other than those to indicate adult males about their readiness for mating or to refuse male approaches.

Mother with calf pairs (MC) showed the highest value for surface activity level 4, indicating they spend a higher proportion of their time resting or moving with lower surface activity than other classes, something also reported by Herman and Antinoja (1977) in Hawaii. This low rate of surface activity was also accompanied by a low velocity displacement, since mother/calf pairs had the lowest speed of all age-classes. This was expected because calves are not strong enough to maintain the velocity of an adult, requiring resting and breathing more often. However, Mate et al. (1998) reported that the mean speed of a female with calf $(5.41 \mathrm{~km} / \mathrm{h})$ was the highest of six whales followed by satellite telemetry. Tyack and Whitehead (1983) also reported that a mother with a calf swam over $12 \mathrm{~km} / \mathrm{h}$ when were chased by other whales. It is expected that calves are able to follow the speed of adults at an early age to stand the migration toward feeding grounds. No evident change in whale speed was noticed under different levels of surface activity. However, the speed estimated is likely downward biased because the method used did not consider the changes in direction during the observation period. This could affect especially to more active groups engaged in social activities. For example, the average speed of competitive groups was estimated in $4.62 \mathrm{~km} / \mathrm{h}(\mathrm{n}=12)$, slightly over the global average $(4.53 \mathrm{~km} / \mathrm{h})$. In some cases the estimated speed was as low as 0.81 and $1.23 \mathrm{~km} / \mathrm{h}$, which in fact would indicate rather that whales were 
pursuing around a small area. On the other hand, the maximum speed estimated for a competitive group was $11.39 \mathrm{~km} / \mathrm{h}$, which probably gives a realistic idea of the speed that such groups may reach. This variability in whale speed is concordant with other reports from breeding whales. Frankel et al., (1995) reported speeds between 1.62 and $11.07 \mathrm{~km} / \mathrm{h}$ for singers and of $4.62 \mathrm{~km} / \mathrm{h}$ (maximum $8.09 \mathrm{~km} / \mathrm{h}$ ) for non-singing singleton whales. Using satellite telemetry, Mate et al. (1998) reported speeds between 60 and $80 \mathrm{~km} /$ day $(2.5-3.33 \mathrm{~km} / \mathrm{h})$ for inter islands moving whales and between 110 and $150 \mathrm{~km} /$ day $(4.58-6.25 \mathrm{~km} /$ h) for migrating whales.

When calves grow and escorts join the pair (ME groups), surface activity increased and the periods without surface displays would reduce. Mother/calf pairs exhibited the highest proportion of the head-slapping display of all age classes. Calves performed them more frequently, also reported by Herman and Tavolga (1980). In contrast, MC groups exhibited the highest proportion of the tail-slashing display. In this case, the mother was the responsible for such display, possibly as an annoyance manifestation or warning signal toward approaching boats. Under a different context, tail-slashing has been considered as a form of aggression toward other males (Silber, 1986; Darling et al, 1983; Baker Herman, 1984; Tyack and Whitehead 1993) and used for defense from killer whales (Chittleborough, 1953). Mother/calf groups had the lowest proportion of displays implicating percussion sounds, possibly because the sight and touch are the main communication senses at this stage when calves are small and remain close to their mothers all the time. Percussion sounds, especially those produced by flipper slapping, would be related with exercising of young calves.

\section{Environment influence}

Notwithstanding some diurnal variability, humpback whales likely have a similar level of surface activity through day hours (06:00-18:00). However, the peak of surface activity at afternoon hours (13:00-16:00) coincides with the period of highest conspicuous behaviors reported by Scott and Winn (1980) in humpback whales breeding at West Indies (15:0016:00). The ability of humpback whales to produce short range percussion sounds at slapping on the surface may be also useful to maintain the social structure of groups by night.

It has been suggested that the sea state may influence the level of activity of humpback whales (Herman and Antinoja, 1977). A similar trend to increase the surface activity in rougher sea found in this study was also reported by Scott and Winn (1980). A rough sea may reduce water visibility, especially in shallow waters where humpbacks breed, thus increase the background noise and thus reducing the effectiveness of the short-range percussion communication, forcing whales to increase the noise production frequency through breaching or slapping to maintain some level of acoustic contact. Despite a trend to increase the surface activity level 1 and decrease level 2 during Beaufort 3 respect to Beaufort 2, no significant difference was found likely because of the disproportion of frequencies in both sea state conditions. However, fewer differences found in less visible groups (levels 3 and 4) suggest that a change in the sighting probability would not be the cause of the differences found in more active groups (levels 1 and 2). Therefore, it is not discarded that the sea state may influence the surface activity of humpback whales although a larger sample is required for a deeper evaluation.

Other environmental factors with a large-scale influence such as the moon phase and "El Niño" event did not show a relationship with the whales level of surface activity. Whale behavior, and hence, the necessity of reproduction, did not seem affected by drastic environmental changes, not even being so dramatic as those presented during "El Niño" 1997-1998. Felix and Haase (2001b) showed that despite the considerable raise in surface water temperature during the breeding season 1997, humpback whales did not show changes in key ecological and biological aspects such as distribution, abundance and reproduction rate. This article indicates that neither surface behavior was affected by these events.

The analysis of the humpback whale surface activity in this paper indicates that there seems to be specific social conditions under which it may be expected an increase or reduction of the frequency of displays exhibited at surface. Social aspects such as organization, male competence and nursing prevailed over the possible influence of environment factors such as day hour, tide cycle, moon phase or sea state. The complex nature of the humpback whale sociality requires major efforts and more appropriate approaches to evaluate the surface activity and understand the different social contexts in which this activity is produced.

\section{Acknowledgements}

The author would like to thank the owners of the boats and tour agencies for allowing the use of their vessels as research platforms. Ben Haase helped me collect data during most of the seasons. Jorge Urban read an early Spanish version of the manuscript and made valuable suggestions. An anonymous reviewer also contributed with important suggestions to improve the final version. The Whale and Dolphin Conservation Society (WDCS) supported the fieldwork.

\section{References}

Au, W.W.L., Mobley, J.M., Burgess, W.C., Lammers, M.O. and Natchtigall, P.E. (2000) Seasonal and diurnal trends of chorusing humpback whales wintering in waters off Western Maui. Marine Mammal Science 16(3): 530-544.

Baker, C.S. and Herman, L.M. (1983) Aggressive behavior between humpback whales (Megaptera novaeangliae) wintering in Hawaiian waters. Canadian Journal of Zoology 62: 1922-1937.

Barber, R.T. and Chavez, F.P. (1983) Biological consequences of El Niño. Science 222: 1203-10.

Brown, M.R. and Corkeron, P.J. (1995) Group characteristics of migrating humpback whales (Megaptera novaeangliae) migrating off Point Lookout, Queensland. Behaviour 132: 163-179. 
Chittleborough, R.G. (1953) Aerial observations on the humpback whale Megaptera nodosa (Bonnaterre), with notes on other species. Australian Journal of Marine and Freshwater Research 4: 219-226.

Clarke, R. (1962) Whale observation and whale marking off the coast of Chile in 1958 and from Ecuador and beyond the Galapagos Islands in 1959. Hvalfangst Tidente 7: 265-287.

Clapham P.J., Palsboll, P.J., Matilla, D.K. and Vasquez, O. (1992) Composition and dynamics of humpback whale competitive groups in the West Indies. Behaviour 122: 182-194.

Craig, A.S., Herman, L.M. and Pack, A.A. (2002) Male mate choice and male-male competition coexist in the humpback whale (Megaptera novaeangliae) Canadian Journal of Zoology 80: 745-755.

Darling, J.D. and Bérubé, M. (2001) Interactions of singing humpback whales with other males. Marine Mammal Science 17(3): 570-584

Darling, J.D., Gibson, K.M. and Silber, G.K. (1983) Observations on the abundance and behavior of humpback whales (Megaptera novaeangliae) off West Maui, Hawaii, 1977-79. Pages 201-222 in Communication and Behavior of Whales. Payne, R. (Ed.) Westview Press, Boulder, CO.

Félix, F. and Haase, B. (1998) La investigación de la ballena jorobada (Megaptera novaeangliae) alrededor de la isla de La Plata, Manabí, durante 1995. Acta Oceanográfica del Pacífico 9(1): 219-227.

Félix, F. and Haase, B. (2001a) The humpback whale off the coast of Ecuador, population parameters and behavior. Revista de Biología Marina y Oceanografía 36(1): 61-74.

Félix F. and Haase, B. (2001b) A note on humpback whales off the Ecuadorian coast during the 1997 "El Niño" event. Journal of Cetacean Research and Management 3(1): 59-64.

Flórez L. (1991) Humpback whales Megaptera novaeangliae in the Gorgona Island, Colombian Pacific breeding waters: population and group characteristics. Memoirs of the Queensland Museum 30: 291-295.

Frankel, A.S., Clark, C.W., Herman, L.M. and Gabriele, C.M. (1995) Spatial distribution, habitat utilization, and social interactions of humpback whales, Megaptera novaeangliae, off Hawaii, determined using acoustic and visual techniques, Canadian Journal of Zoology 73: 1134-1146.

Herman, L.M. and Antinoja, R.C. (1977) Humpback whales in the Hawaiian breeding waters: Population and group characteristics. Scientific Reports, Whales Research Institute 29: 59-85.

Herman, L.M. and Tavolga, W.N. (1980) The communication systems of Cetaceans. Pages 149-209 in Cetacean Behavior: Mechanisms \& Functions. Herman, L.M. (Ed.) John Wiley \& Sons. New York. 463pp.

Leatherwood, S. and Reeves, R.R. (1983) The Sierra Club Handbook of Whales and Dolphins. Sierra Club Books. San Francisco. 302pp.
Mate, B.R., Gisiner, R, and Mobley, J. (1998) Local and migratory movements of Hawaiian humpback whales tracked by satellite telemetry. Canadian Journal of Zoology 76(5): 863-868.

Mobley, J.R. and Herman, L.M. (1985) Transience of social affiliations among humpback whales (Megaptera novaeangliae) on the Hawaiian wintering grounds. Canadian Journal of Zoology 63: 762-772.

Ojeda, Z.V. and Hurtado, L.A. (1992) Aspectos biológicos de la yubarta Megaptera novaeangliae durante su ciclo reproductivo en la isla Gorgona, 1991. Memorias del VIII Seminario de Ciencias y Tecnologias del Mar y Congreso Centroamericano y del Caribe de Ciencias del Mar. Santa Marta. Colombia. p.697-708.

Payne, R. and McVay, S. (1971) Songs of the humpback whales. Science 173: 585-597.

Saayman, G.S. and Tayler, C.K. (1973) Some behavior patterns of the southern right whale, Eubalaena australis. Zeitschrift für Saugetierkunde 3: 172-183.

Scheidat M, Castro, C., Denkinger, J., González, J. and Adelung, D. (2000) A breeding area for humpback whales (Megaptera novaeangliae) off Ecuador. Journal of Cetacean Research and Management 2(3): 165-171.

Scott, G.P. and Winn H.E. (1979) Comparative evaluation of aerial and shipboard sampling techniques for estimating the abundance of humpback whales (Megaptera novaeangliae). Final Report to U.S. Marine Mammal Commission. Contract MM7AC029. 95p.

Silber, G.K. (1986) The relationship of social vocalizations to surface behavior and aggression in the Hawaiian humpback whale (Megaptera novaeangliae). Canadian Journal of Zoology 64: 2075-2080.

Slijper, E.J. (1979) Whales. Cornell University Press, Ithaca New York. 511pp.

Smultea, M.A. (1994) Segregation by humpback whale (Megaptera novaeangliae) cows with calves in coastal habitat near the island of Hawaii. Canadian Journal of Zoology 72: 805-811.

Spitz, S.S., Herman, L.M., Pack, A.A. and Deakos, M.H. (2002) The relation of body size of male humpback whales to their social roles on the Hawaiian winter grounds. Canadian Journal of Zoology 80(11): 1917-1938.

Tyack, P. (1981) Interactions between singing Hawaiian humpback whales and conspecifics nearby. Behavior Ecology and Sociobiology 8: 105-116.

Tyack, P. and Whitehead, H. (1983) Male competition in large s of wintering humpback whales. Behaviour 83: 132-154.

Valsecchi, E., Hale, P., Corkeron, P. and Amos, W. (2002) Social structure in migrating humpback whales (Megaptera novaeangliae). Molecular Ecology (2002) 11: 507-518.

Whitehead, H. (1982) Structure and stability of humpback whale groups off Newfoundland. Canadian Journal of Zoology 61: 1391-1397.

Winn, H.E. and Winn, L.K. (1978) The song of the humpback whale, Megaptera novaeangliae, in the West Indies. Marine Biology 47: 97-114. 